\title{
Substratos e intensidades de luz no cultivo de orquídea denfal
}

\author{
Marichel C Macedo; Yara BCJ Rosa; Silvana de PQ Scalon; Edgard J Rosa Junior; Maria do C Vieira; \\ Mariana B Tatara
}

UFGD-FCA, Rod. Dourados - Itahum, km 12, 79804-970 Dourados-MS; marichelcanazza@zipmail.com.br; yarachaim@hotmail.com; silvanascalon@ufgd.edu.br; jjunior@ceud.ufms.br; vieiracm@terra.com.br; marianabtatara@gmail.com

\section{RESUMO}

Foi avaliada a influência da luminosidade e de substratos alternativos ao xaxim, no desenvolvimento e floração de plantas de Dendrobium phalaenopsis var. schroederianum $\mathbf{x}$ Dendrobium bigibbum var. compactum. O experimento foi conduzido na UFGD-FCA, de outubro de 2007 a agosto de 2008. Foram utilizadas plantas com quatro anos oriundas de cultivo in vitro, aclimatizadas em viveiro com intensidade luminosa de 12.800, 8.300, 6.200, 5.300 e 4.500 lux, e plantadas em vasos plásticos contendo como substrato carvão, fibra de coco ou uma mistura de carvão + fibra de coco. Durante o período experimental foram avaliados a redução de massa fresca (\%), o diâmetro de pseudobulbos (\%), brotações (\%), início da floração, plantas com flores (\%), comprimento da haste floral, botões florais $\left(\mathrm{n}^{\circ}\right)$, diâmetro das flores e duração do florescimento. As menores reduções da massa fresca e do diâmetro foram observados sob 12.800 lux. Para brotações os maiores valores foram observados em substrato carvão sob 12.800 lux, ou em substrato fibra de coco e carvão + fibra de coco sob 4.500 lux. Nas condições em que o trabalho foi conduzido recomenda-se que esta orquídea seja cultivada em carvão sob 12.800 lux, uma vez que o maior percentual de plantas com flores, número de botões por planta, diâmetro das flores e comprimento da haste floral produzidos foram observados nestas condições.

\begin{abstract}
Substrates and light intensity on cultivation of Denphal orchid

The influence of light and alternative substrates to fern tree fiber was evaluated on the development and flowering of Dendrobium phalaenopsis var. schroederianum x Dendrobium bigibbum var. compactum plants. The experiment was carried out from October 2007 to August 2008. Four-year old plants from in vitro cultivation, and acclimatized in nursery with light intensities of 12,800, 8,300, $6,200,5,300$ and 4,500 lux, were used. Plants were planted in plastic vases filled with charcoal, coconut fiber or a mix of charcoal + coconut fiber as substrate. During the experimental period, the reduction of fresh mass (\%) and diameter of pseudobulbs, sprouting (\%), beginning of flowering, plants with flowers (\%), length of the flower stem, flower buds $\left(\mathrm{n}^{\circ}\right)$, diameter of flowers and time of flowering were evaluated. The smallest reduction of fresh mass and of diameter were observed under 12,800 lux. For sprouting, the highest values were observed with charcoal substrate under 12,800 lux, or with coconut fiber substrate and charcoal + coconut fiber substrate under 4,500 lux. This orchid should be cultivated with charcoal under 12,800 lux, since the highest percentage of plants with flowers, number of buds per plant, diameter of flowers and length of the flower stem were produced under those conditions.
\end{abstract}

Keywords: coconut fiber, charcoal, shading.

Palavras-chave: fibra de coco, carvão, sombreamento.

(Recebido para publicação em 27 de outubro de 2009; aceito em 11 de abril de 2011)

(Received on October 27, 2009; accepted on April 11, 2011)

\begin{abstract}
A família Orchidaceae possui grande diversidade de espécies e híbridos. Suas flores destacam-se pelo tamanho, forma e combinação de cores, características que contribuem cada vez mais para a sua apreciação. Na floricultura, muitas espécies são comercializadas como planta envasada e, atualmente, devido ao aumento da demanda, o cultivo de espécies com características de flores de corte é promissor (Mattiuz et al., 2006).

As exportações brasileiras de mudas de orquídeas em 2007 foram de US\$ 233,91 mil, apresentando um crescimento de 43,62\% em relação a 2006 (Junqueira \& Peetz, 2007). Os gêneros mais promissores para exportação da floricultura tropical brasileira são Oncidium, Cymbidium, Dendrobium e
\end{abstract}

Cattleya que se destacam por já participar do mercado com exportações de flores de corte, para países como o Japão e os Estados Unidos (Mattiuz et al., 2006).

Dentre as espécies do gênero Dendrobium, o D. phalaenopsis Fitzgerald, conhecido por denfal, é uma das mais populares plantas de corte do comércio mundial de flores (Men et al., 2003). A espécie é nativa da Oceania, apresenta inflorescências com diferentes comprimentos e número de flores por haste floral (Betchel et al., 1985; Roriz, 2000), além de coloração variada, florescendo no Brasil durante o outono e inverno.

O hibrido estudado neste trabalho, Dendrobium phalaenopsis var. schroederianum $\mathbf{x}$ Dendrobium bigibbum var. compactum, produz hastes florais com 4 a 8 flores de diâmetros de 4 a $5 \mathrm{~cm}$, florescendo entre março e julho durante aproximadamente 30 dias. Plantas sem flores são comercializadas por $\mathrm{R} \$ 5,00$ a $\mathrm{R} \$ 20,00$ e floridas de $\mathrm{R} \$ 10,00$ a $\mathrm{R} \$ 30,00$ dependendo do tamanho da planta e da quantidade de hastes e flores.

Para o cultivo de muitas orquídeas em recipientes, o substrato utilizado exerce influência na qualidade do produto final, devendo, portanto, apresentar características físicas e químicas ideais ao crescimento da planta e custo acessível ao produtor (Assis et al., 2005; Jasmim et al, 2006).

O xaxim permaneceu como base 
para o preparo de substratos de várias espécies de plantas ornamentais no Brasil, sendo o material preferido da maioria dos orquidários comerciais. No entanto, devido ao extrativismo desenfreado sua extração e comercialização estão proibidas, acarretando uma grande demanda por materiais que possam substituí-lo. (Jasmim et al., 2006).

Uma alternativa de baixo custo para substituir o xaxim consiste na utilização de resíduos agroindustriais de fácil obtenção. A caracterização e a avaliação desses materiais como substrato agrícola pode ser uma importante alternativa de reciclagem (Costa et al, 2007) minimizando o impacto ambiental provocado por tais resíduos.

A casca de coco verde, subproduto do uso e da industrialização da água de coco, pode ser processada para beneficiamento de fibras longas, curtas ou pó e tem sido utilizada como substrato no cultivo de hortaliças e flores (Rosa et al., 2001; Carrijo et al., 2002). Alguns trabalhos têm demonstrado a eficiência do uso da fibra de coco como substrato na produção de plantas ornamentais, tais como, Tillandsia kautskyi E. Pereira (Demattê, 2005), Cryptanthus sinuosus L.B. Smith (Jasmim et al., 2006), e das orquídeas Dendrobium nobile Lindl., (Assis et al., 2005) e Oncidium baueri Lindl. (Assis et al., 2008).

Outro tipo de substrato recentemente introduzido no Brasil é o fino do carvão, subproduto da produção de carvão vegetal. O fino do carvão vegetal, obtido no processo de peneiramento na classificação do carvão vegetal, tem uma estrutura altamente porosa que, se misturado ao solo ou substrato pode aumentar a porosidade, a capacidade de retenção de água e facilitar a proliferação de microorganismos benéficos (Zanetti et al., 2003).

Além do substrato, a luminosidade exerce influência na produtividade de orquídeas. Alta intensidade luminosa pode causar fotoinibição assim como luminosidade insuficiente resulta em diminuição da taxa de fotossíntese, na biomassa e na produção, podendo ainda afetar o transporte de fotoassimilados e a relação fonte:dreno (Souza et al., 1999).

Considerando a necessidade de se estabelecer métodos de cultivo para melhor produção de denfal e de buscar alternativas ao uso do xaxim, este trabalho teve como objetivos comparar o desenvolvimento do híbrido Dendrobium phalaenopsis var. schroederianum $\mathbf{x}$ Dendrobium bigibbum var. compactum sob diferentes níveis de luminosidade e substratos.

\section{MATERIAL E MÉTODOS}

O experimento foi conduzido na área de Jardinocultura da UFGD-FCA em Dourados-MS (22 $12^{\circ} 16^{\prime} \mathrm{S}$ e $54^{\circ}$ 48 '02"W, altitude média de $452 \mathrm{~m}$ ), de outubro de 2007 a agosto de 2008 . As médias máxima e mínima anuais de temperatura do ar são de 24 e $20^{\circ} \mathrm{C}$, respectivamente, com precipitação total anual entre 1.250 e $1.500 \mathrm{~mm}$. O clima regional é do tipo Cwa mesotérmico úmido, segundo a classificação de Köppen (1948).

Como material de estudo foram utilizadas plantas de 12 meses, oriundas de semeadura in vitro provenientes do cruzamento de Dendrobium phalaenopsis var. schroederianum $\mathbf{x}$ Dendrobium bigibbum var. compactum que, após serem removidas dos frascos de cultivo, foram aclimatizadas por três anos, em viveiro com $50 \%$ de sombreamento (12.800 lux de luminosidade), em substrato constituído por fibra de coco (chips da Amafibra $\left.{ }^{\circledR}\right)$, apresentando altura média em torno de $11 \mathrm{~cm}$.

Após a completa remoção do substrato de aclimatização, as plantas foram avaliadas quanto à massa fresca e ao diâmetro da porção mais dilatada dos pseudobulbos sendo, a seguir, plantadas em vasos plásticos pretos com capacidade de $1000 \mathrm{~cm}^{3}$, contendo na parte inferior, como camada de drenagem, $200 \mathrm{~cm}^{3}$ de brita número 3 previamente esterilizada em autoclave. Os outros $800 \mathrm{~cm}^{3}$ foram preenchidos com um dos seguintes substratos: 1) carvão de diâmetro entre 5 e $10 \mathrm{~mm}, 2$ ) fibra de coco (chips da Amafibra ${ }^{\circledR}$ ) e 3 ) carvão de diâmetro entre 5 e $10 \mathrm{~mm}+$ fibra de coco (mistura manual obtida pela pesagem de $400 \mathrm{~cm}^{3}$ de carvão e $400 \mathrm{~cm}^{3}$ de fibra de coco).

Os substratos foram caracterizados quanto à macroporosidade, à microporosidade, à porosidade total, à capacidade máxima de retenção de água e à densidade conforme Trigueiro \& Guerrini (2003). Os valores médios desses atributos físicos são apresentados na Tabela 1 .

Após o plantio, os vasos contendo uma planta cada, foram alocados em bancadas localizadas no interior de um viveiro coberto com tela de $50 \%$ de sombreamento. Sobre cada conjunto de 30 vasos (10 de cada substrato estudado), foi instalada uma estrutura metálica, em forma de túnel baixo, com dimensões de $0,8 \times 1,3 \mathrm{~m}$ e altura de $0,6 \mathrm{~m}$, denominadas de subcobertura, que receberam telas de $30,40,50$ e $70 \%$ de sombreamento, as quais propiciaram, durante o período experimental, intensidade luminosa média de 8.300, 6.200, 5.300 e 4.500 lux, respectivamente. Um conjunto de 30 vasos, considerado como controle, não recebeu subcobertura, sendo protegido apenas pela tela do viveiro e submetido a 12.800 lux.

Os valores de luminosidade foram coletados diariamente às $7,9,11,13,15$ e $17 \mathrm{~h}$, com o auxílio de um luxímetro digital, sob cada condição de sombreamento, sendo a seguir calculada uma média diária e posteriormente uma média do período experimental que resultou nos valores anteriormente citados.

Durante o período experimental as plantas foram irrigadas duas vezes por dia e adubadas quinzenalmente, via foliar, com NPK 10-10-10 na concentração de 2,0 mL L-1 (adubação básica praticada nos orquidários da UFGD). A irrigação por microaspersão foi feita nos períodos matutino e vespertino durante 15 minutos, adicionando-se, em média, $2 \mathrm{~mm}$ de água por turno de rega.

No período de abril a agosto de 2008 foram avaliadas as características reprodutivas: início da floração (IF): número de dias decorridos entre o transplante e a abertura do botão basal da haste floral; comprimento da haste floral $(\mathrm{CH})$ : comprimento entre a inserção da haste floral no pseudobulbo e a inserção do botão apical na haste; número de botões florais por planta (NB); diâmetro da flor (Dflor): média de três medições por flor, relativas à distância entre os ápices de cada pétala e sépala correspondente; duração da floração (DF): período entre a abertura e o murchamento do primeiro 
botão floral (dias); e plantas com flores (\%PF).

No final do período experimental, as plantas foram removidas dos vasos e lavadas em água corrente até total remoção dos substratos, e a seguir foram avaliadas quanto à massa fresca e diâmetro da porção mais dilatada dos pseudobulbos. Nessa ocasião também foram contados o número de brotações. A partir da diferença entre os valores finais e iniciais dessas características foram calculados a redução de massa fresca (\%RMF) e o diâmetro de pseudobulbos $(\% \mathrm{RD})$, além do percentual de brotações (\%BR).

$\mathrm{O}$ delineamento experimental utilizado foi inteiramente casualizado e os tratamentos foram arranjados em esquema de parcelas subdivididas, sendo as parcelas constituídas pelos cinco níveis de intensidade luminosa e as subparcelas pelos três substratos. Para as características vegetativas e para a \%PF e IF foram utilizadas 10 repetições constituídas por uma planta cada e para as demais características reprodutivas 3 repetições de uma planta cada.

Para as análises estatísticas foi utilizado o aplicativo computacional SAEG (Ribeiro Junior, 2001) e todas as características foram avaliadas mediante análise de variância e, havendo significância, os fatores qualitativos foram comparados por teste de médias (Tukey a 5\% de probabilidade) e os quantitativos por análise de regressão (Banzato \& Kronka, 1992).

\section{RESULTADOS E DISCUSSÃO}

Em relação às características vegetativas, constatou-se efeito isolado da intensidade luminosa $(\mathrm{p}<0,05)$ apenas sobre o percentual de redução da massa fresca $(\% \mathrm{RMF})$ das plantas, não sendo entretanto observado efeito isolado dos substratos $(\mathrm{p}>0,05)$ sobre qualquer característica estudada. Por outro lado, houve efeito conjunto dos tratamentos $(\mathrm{p}<0,05)$ sobre o percentual de brotações (\%BR) e sobre o percentual de redução do diâmetro de pseudobulbos (\%RD) das plantas.

$\mathrm{Na}$ Figura 1a pode-se observar que o aumento da intensidade luminosa propiciou os menores valores de $\% \mathrm{RMF}$

Tabela 1. Atributos físicos dos substratos utilizados para o cultivo de plantas Dendrobium phalaenopsis var. schroederianum $\mathbf{x}$ Dendrobium bigibbum var. compactum (physical characteristics of substrates used in Dendrobium phalaenopsis var. schroederianum $\mathbf{x}$ Dendrobium bigibbum var. compactum plants cultivation). Dourados, UFGD, 2008.

\begin{tabular}{lccc}
\hline Atributos & Carvão & $\begin{array}{c}\text { Fibra de } \\
\text { coco }\end{array}$ & $\begin{array}{c}\text { Carvão }+ \\
\text { fibra de coco }\end{array}$ \\
\hline Macroporosidade (\%) & 27,80 & 43,60 & 36,00 \\
Microporosidade (\%) & 27,90 & 36,30 & 35,70 \\
Porosidade total (\%) & 55,80 & 79,90 & 68,00 \\
Cap. retenção de água (mL/50 cm c $\left.^{3}\right)$ & 14,60 & 19,60 & 18,90 \\
Densidade g/cm & 0,19 & 0,04 & 0,15 \\
\hline
\end{tabular}

Tabela 2. Efeito dos substratos sobre a redução do diâmetro de pseudobulbos (\%) e sobre brotações de plantas (\%) de Dendrobium phalaenopsis var. schroederianum $\mathbf{x}$ Dendrobium bigibbum var. compactum hybrids (substrates effects on reduction of diameter of pseudobulbs $(\%)$ and sprouting (\%) of Dendrobium phalaenopsis var. schroederianum $\mathbf{x}$ Dendrobium bigibbum var. compactum plants). Dourados, UFGD, 2008.

\begin{tabular}{lccrrr}
\hline \multirow{2}{*}{ Substratos } & \multicolumn{5}{c}{ Intensidade luminosa (lux) } \\
\cline { 2 - 6 } & $\mathbf{4 . 5 0 0}$ & $\mathbf{5 . 3 0 0}$ & $\mathbf{6 . 2 0 0}$ & $\mathbf{8 . 3 0 0}$ & $\mathbf{1 2 . 8 0 0}$ \\
\cline { 2 - 6 } & $13,89 \mathrm{~b}$ & $16,65 \mathrm{ab}$ & $7,51 \mathrm{a}$ & $21,37 \mathrm{a}$ & $6,95 \mathrm{a}$ \\
\hline Carvão & $34,54 \mathrm{a}$ & $30,15 \mathrm{a}$ & $17,68 \mathrm{a}$ & $4,35 \mathrm{a}$ & $11,67 \mathrm{a}$ \\
Fibra de coco & $15,67 \mathrm{ab}$ & $10,37 \mathrm{~b}$ & $11,87 \mathrm{a}$ & $16,22 \mathrm{a}$ & $12,35 \mathrm{a}$ \\
Carvão + Fibra de coco & $1,00 \mathrm{~b}$ & $2,00 \mathrm{a}$ & $6,00 \mathrm{a}$ & $9,00 \mathrm{a}$ & $14,00 \mathrm{a}$ \\
\hline \multicolumn{5}{c}{ Brotações (\%) } \\
\hline Carvão & $12,00 \mathrm{a}$ & $6,00 \mathrm{a}$ & $6,00 \mathrm{a}$ & $7,00 \mathrm{a}$ & $3,00 \mathrm{~b}$ \\
Fibra de coco & $10,00 \mathrm{ab}$ & $4,00 \mathrm{a}$ & $7,00 \mathrm{a}$ & $10,00 \mathrm{a}$ & $2,00 \mathrm{~b}$ \\
Carvão + Fibra de coco & 10,00 diâmetro de pseudobulbos (\%) \\
\hline
\end{tabular}

Médias seguidas de mesma letra minúscula na coluna não diferem estatisticamente entre si pelo teste de Tukey a 5\% de probabilidade (means followed by the same small letter in the column, did not differ from each other by Tukey's test at $5 \%$ of probability).

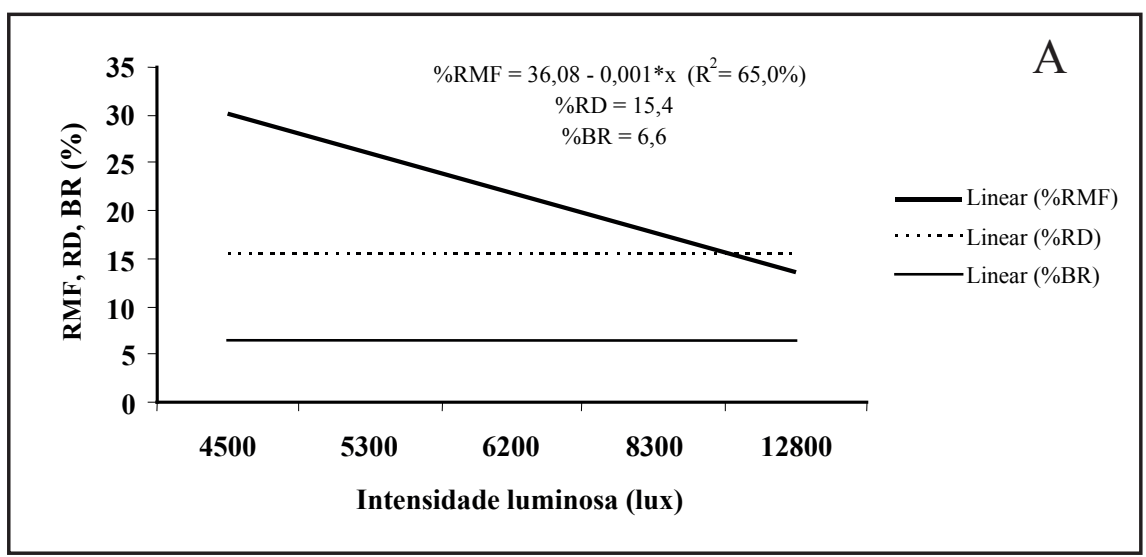

Figura 1 A) Efeito isolado da intensidade luminosa sobre redução de massa fresca (\%RMF), redução do diâmetro de pseudobulbos (\%RD) e brotações (\%BR) (A) light intensity on reduction of fresh mass $(\% \mathrm{RMF})$, reduction of pseudobulbs diameter $(\% \mathrm{RD})$ and sprouting (\%BR). Dourados, UFGD, 2008.

e, independentemente da intensidade luminosa utilizada, o \%RD e o \%BR apresentaram valores médios de 15,42 e 6,6 , respectivamente.
$\mathrm{O}$ efeito conjunto dos tratamentos sobre o \%RD é apresentado na Figura 1b. Houve efeito da intensidade luminosa apenas quando se utilizou a fibra de 


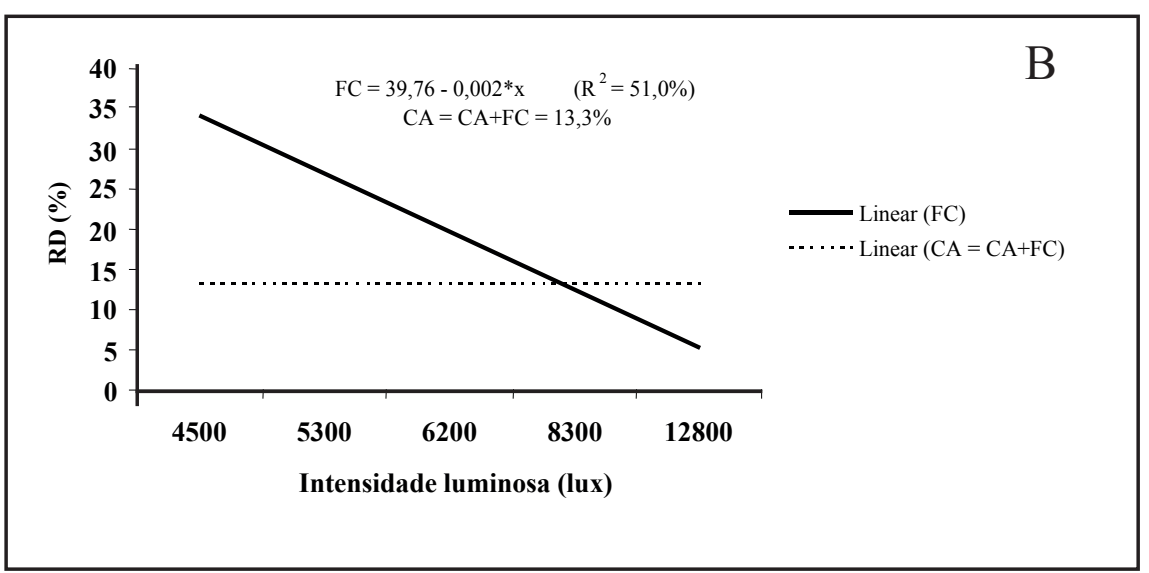

Figura 1 B) Efeito conjunto das intensidades luminosas e dos substratos sobre a redução do diametro de pseudobulbos (\%RD) de plantas de Dendrobium phalaenopsis var. schroederianum $\mathbf{x}$ Dendrobium bigibbum var. compactum $. \mathrm{CA}=$ carvão; $\mathrm{FC}=$ fibra de coco; $\mathrm{CA}+\mathrm{FC}=$ carvão + fibra de coco (B) Light intensity and substrates effects on reduction of pseudobulbs diameter (\%RD) of Dendrobium phalaenopsis var. schroederianum $\mathbf{x}$ Dendrobium bigibbum var. compactum plants. $\mathrm{CA}=$ charcoal; $\mathrm{FC}=$ coconut fiber; $\mathrm{CA}+\mathrm{FC}=$ charcoal + coconut fiber $)$. Dourados, UFGD, 2008.

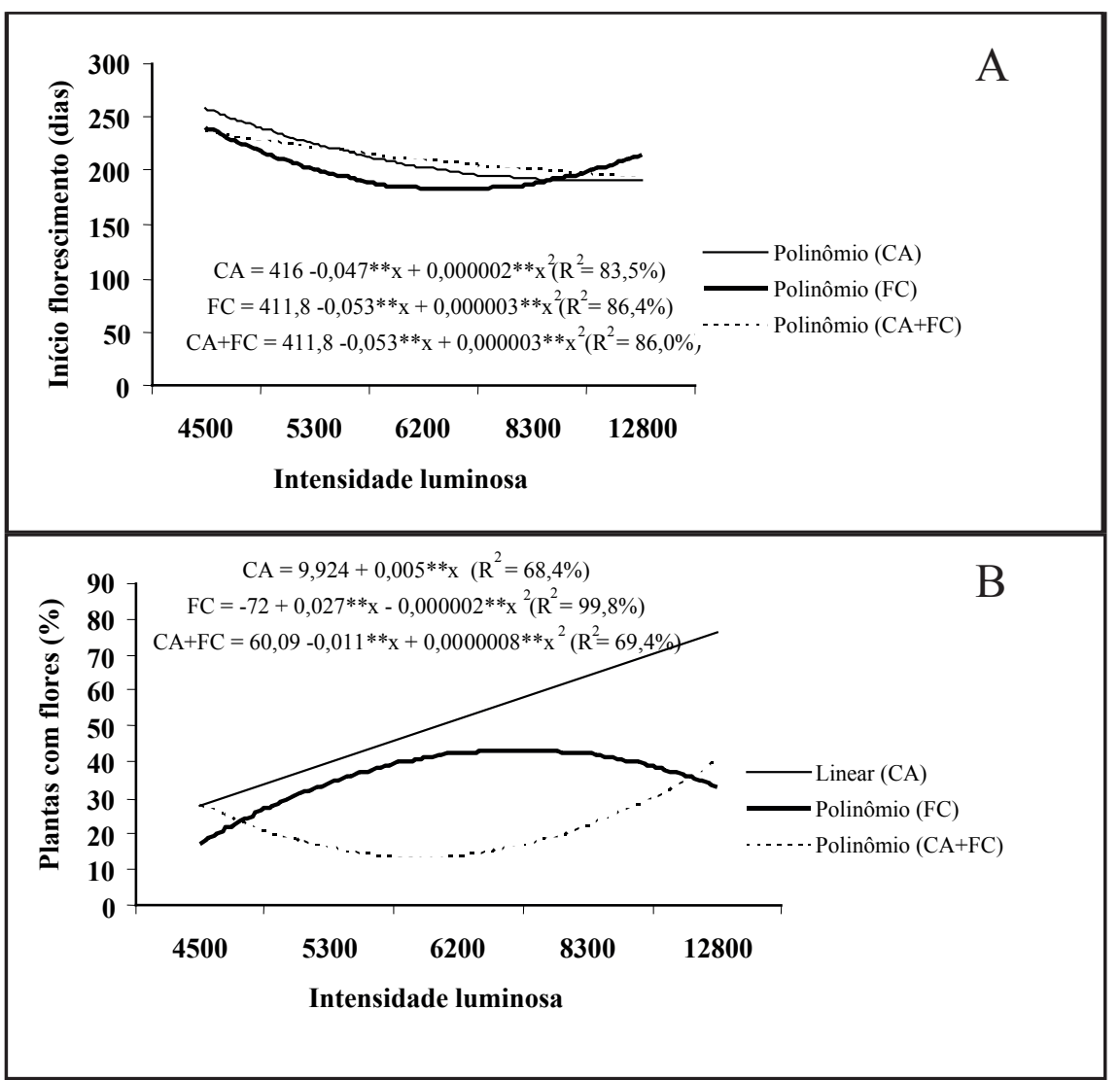

Figura 2. Efeito conjunto da intensidade luminosa e dos substratos a) sobre o início da floração após o transplante e b) sobre o percentual de plantas com flores de plantas de Dendrobium phalaenopsis var. schroederianum $\mathbf{x}$ Dendrobium bigibbum var. compactum. $\mathrm{CA}=$ carvão; $\mathrm{FC}=$ fibra de coco; $\mathrm{CA}+\mathrm{FC}=$ carvão + fibra de coco (light intensity and substrates effects on a) flowering beginning after transplantation and b) on percentage of plants with flowers of Dendrobium phalaenopsis var. schroederianum $\mathbf{x}$ Dendrobium bigibbum var. compactum plants. $\mathrm{CA}=$ charcoal; $\mathrm{FC}=$ coconut fiber; $\mathrm{CA}+\mathrm{FC}=$ charcoal + coconut fiber $).$ Dourados, UFGD, 2008. coco e nestas condições, à medida que se aumentou a intensidade luminosa houve menores perdas nos diâmetros de pseudobulbos. Nos demais substratos o $\%$ RD foi de 13,3 independentemente da intensidade luminosa utilizada (Figura $1 b)$.

Sob 4.500 e 5.300 lux, a fibra de coco proporcionou os maiores valores de $\% \mathrm{RD}$ sendo estatisticamente iguais ao substrato carvão + fibra de coco (em 4.500 lux) e ao carvão (em 5.300 lux) (Tabela 2). A partir de 6.200 lux, o cultivo de plantas de denfal em fibra de coco apresentou valores de \%RD estatisticamente iguais aos proporcionados pela utilização do carvão e da mistura de carvão + fibra de coco (Tabela 2). Esses resultados podem sugerir que a luminosidade próxima da utilizada durante o período de aclimatização das plantas (controle) tenha proporcionado uma condição mais favorável ao cultivo das mesmas, uma vez que o estresse decorrente do transplante foi menos intenso, devido ao seu aparato fotossintético estar já regulado a essa condição de luminosidade. A utilização da fibra de coco e luminosidade inferior a 6.200 lux propiciaram condições de cultivo desfavoráveis às plantas, induzindo maior utilização das reservas hídricas e nutricionais contidas nos pseudobulbos como mecanismo de sobrevivência (Tabela 2).

Em relação ao \%BR, houve efeito dos substratos $(p<0,05)$ quando as plantas foram cultivadas sob 4.500 e 12.800 lux (Tabela 2). Esses resultados sugerem que a produção de brotações de denfal está relacionada ao equilíbrio entre a intensidade luminosa e a disponibilidade hídrica fornecida pelos substratos. Assim, a maior produção de brotações ocorreu tanto em condições de maior luminosidade com a utilização de substrato de menor capacidade de retenção hídrica (carvão), quanto em condições de menor luminosidade com a utilização de substratos de maior retenção hídrica (fibra de coco e carvão + fibra de coco) (Tabela 2).

Em relação às características reprodutivas, constatou-se efeito conjunto dos tratamentos sobre o início do florescimento (IF), o percentual de plantas com flores (\%PF), a duração da floração (DF) 


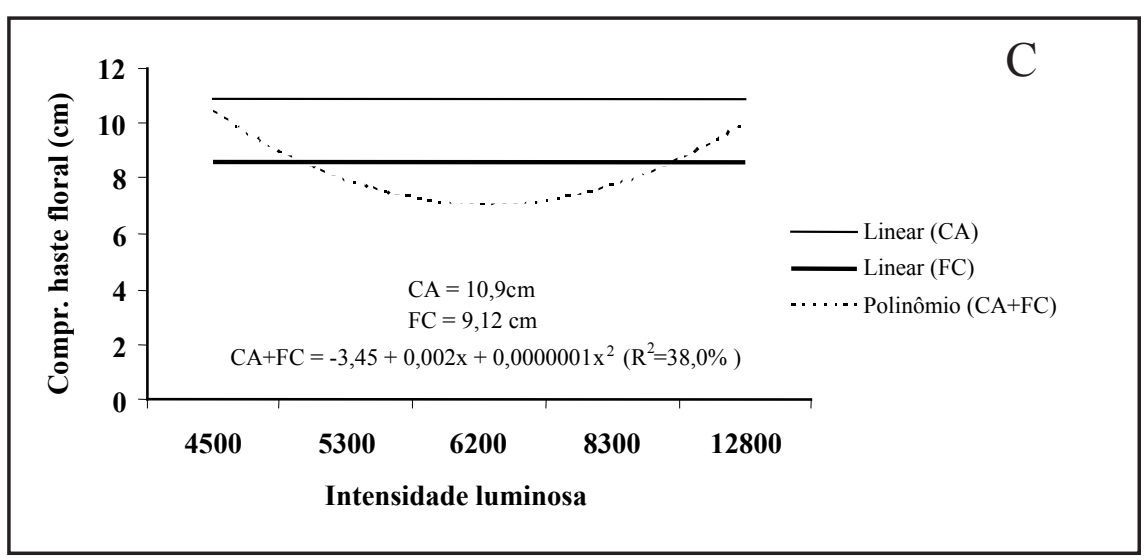

Figura 2. C - Efeito conjunto da intensidade luminosa e dos substratos sobre o comprimento da haste floral de plantas de Dendrobium phalaenopsis var. schroederianum $\mathbf{x}$ Dendrobium bigibbum var. compactum. $\mathrm{CA}=$ carvão; $\mathrm{FC}=$ fibra de coco; $\mathrm{CA}+\mathrm{FC}=$ carvão + fibra de coco (C) light intensity and substrates effects on length of the flower stem of Dendrobium phalaenopsis var. schroederianum $\mathbf{x}$ Dendrobium bigibbum var. compactum plants. $\mathrm{CA}=$ charcoal; $\mathrm{FC}=$ coconut fiber; $\mathrm{CA}+\mathrm{FC}=$ charcoal + coconut fiber). Dourados, UFGD, 2008.
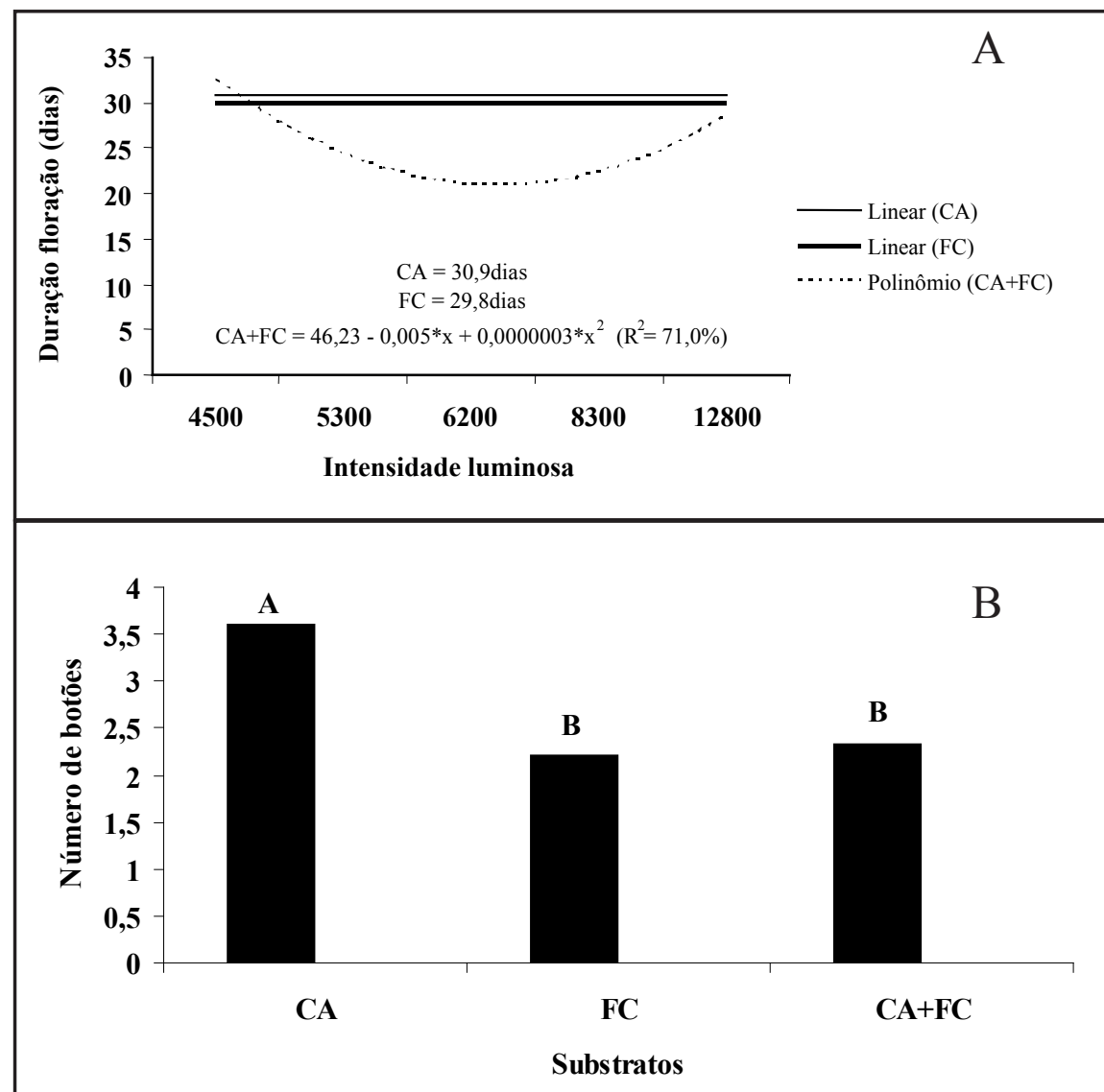

Figura 3. A) Efeito conjunto da intensidade luminosa e dos substratos sobre a duração da floração e B) Efeito do substrato no número de botões de plantas de Dendrobium phalaenopsis var. schroederianum $\mathbf{x}$ Dendrobium bigibbum var. compactum. $\mathrm{CA}=$ carvão; $\mathrm{FC}=$ fibra de coco; $\mathrm{CA}+\mathrm{FC}=$ carvão + fibra de coco $(\mathrm{A})$ Light intensity and substrates effects on duration of flowering and B) substrates effects on number of buds per plant of Dendrobium phalaenopsis var. schroederianum $\mathbf{x}$ Dendrobium bigibbum var. compactum. $\mathrm{CA}=$ charcoal; $\mathrm{FC}=$ coconut fiber; $\mathrm{CA}+\mathrm{FC}=$ charcoal + coconut fiber). Dourados, UFGD, 2008. e o comprimento da haste floral (CHF). Para o número de botões florais (NB) houve efeito isolado dos tratamentos, enquanto que para o diâmetro da flor (Dflor), tanto os substratos quanto os níveis de intensidade luminosa não influenciaram nos resultados observados, apresentando valores médios de 16,24 $\mathrm{mm}$ para esta característica.

O florescimento iniciou-se em abril de 2008, aproximadamente aos 180 dias após o transplante (DAP), sendo observado um retardo no início desse fenômeno em plantas cultivadas sob as menores intensidades luminosas e em substratos constituídos de carvão e carvão + fibra de coco (Figura 2a). Nessas mesmas condições foram observados os menores percentuais de plantas com flores, indicando que a intensidade luminosa possa ter influência na floração de denfal (Figura 2b), além de outros fatores ambientais como temperatura e fotoperíodo (Rotor Junior, 1952).

No entanto, em relação às orquidáceas, pouco se conhece sobre os aspectos fisiológicos de estímulo para a indução da floração. O grande número de espécies desta família distribuídas em diferentes habitats e, consequentemente, submetidas a várias condições ambientais dificulta a compreensão dos fenômenos envolvidos nessa fase, já que os mesmos envolvem respostas das plantas relacionadas à temperatura, fotoperíodo, umidade, intensidade de luz e outros fatores climáticos que podem atuar individualmente ou em conjunto, estimulando a conversão de gemas vegetativas em reprodutivas (Cardoso, 2007).

Em relação ao comprimento da haste floral, o substrato carvão promoveu os maiores valores em todos os níveis de intensidade luminosa, cujos resultados não diferiram estatisticamente entre si (Figura 2c).

Para a duração da floração houve diferença entre os tratamentos, sendo as menores médias (22 dias) observadas em flores produzidas por plantas cultivadas na mistura de carvão + fibra de coco sob 6.200 lux (Figura 3a).

Vários aspectos são considerados importantes na avaliação comercial da qualidade de flores de orquídeas, tais como número de botões para $D$. nobile 


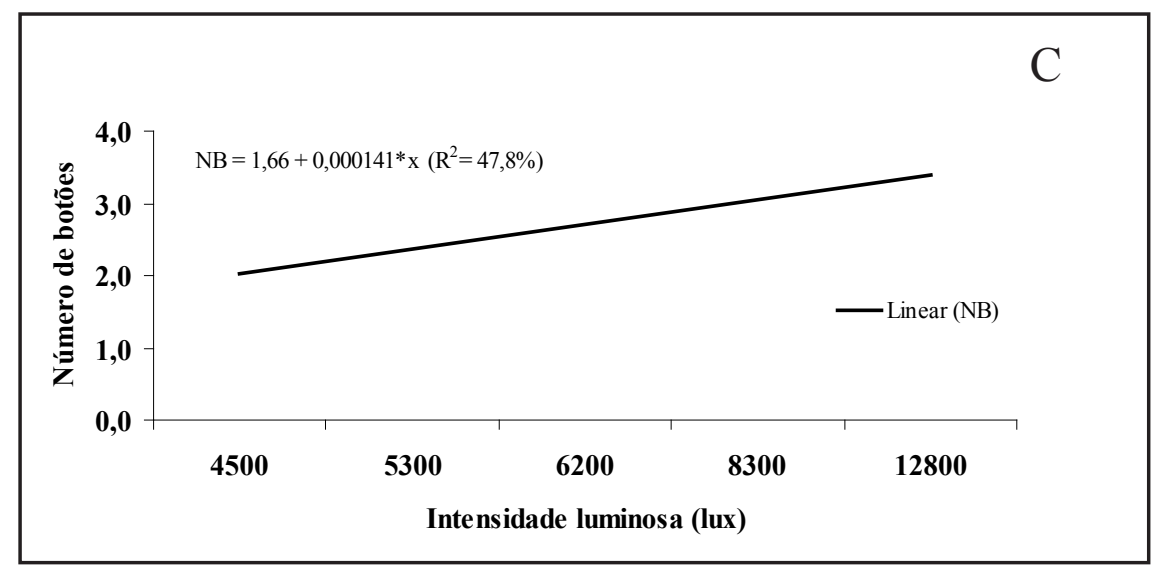

Figura 3. C) Efeito da intensidade luminosa no número de botões de plantas de Dendrobium phalaenopsis var. schroederianum $\mathbf{x}$ Dendrobium bigibbum var. compactum. $\mathrm{CA}=$ carvão; $\mathrm{FC}=$ fibra de coco; $\mathrm{CA}+\mathrm{FC}=$ carvão + fibra de coco $(\mathrm{C})$ Effect of light intensity on number of buds per plant of Dendrobium phalaenopsis var. schroederianum $\mathbf{x}$ Dendrobium bigibbum var. compactum. $\mathrm{CA}=$ charcoal; $\mathrm{FC}=$ coconut fiber; $\mathrm{CA}+\mathrm{FC}=$ charcoal + coconut fiber $)$. Dourados, UFGD, 2008.

(Bernardi et al., 2004) e diâmetro das flores para Phalaenopsis (Cardoso, 2007). Tanto para o cultivo de material de corte quanto para o de envasado, a durabilidade das flores também deve ser levada em conta na avaliação do padrão de qualidade, uma vez que quanto mais tempo as plantas permanecerem com flores abertas, maior a probabilidade de venda e menores são os riscos de perda. Como observado no presente trabalho, as flores de denfal apresentaram durabilidade média de 28 dias período considerado adequado para o híbrido em questão.

O maior número de botões florais foi observado em plantas cultivadas em substrato carvão ( 3 botões por planta) (Figura 3b), sendo observado um aumento crescente em função do aumento da intensidade luminosa (Figura 3c), o que indica a necessidade do híbrido por maior intensidade luminosa e condições de cultivo nos quais haja drenagem eficiente de água, como observado no substrato em estudo.

Deve-se salientar que nessas mesmas condições as plantas cultivadas em carvão e sob 12.000 lux florescem em maior proporção (Figura 2b) a um custo de produção rentável, uma vez que o carvão utilizado como substrato é um subproduto da indústria carvoeira e adquirido sem ônus ou a baixo custo pelos produtores e a condição de 12.800 lux dispensa a utilização de subcobertu-
CARDOSO JC. 2007. Ácido giberélico ( $\left.G A_{3}\right)$ na indução do florescimento de orquídeas. Botucatu: Universidade Estadual Paulista. 50p. (Dissertação mestrado).

COSTA CA; RAMOS SJ; SAMPAIO RA; GUILHERME DO; FERNANDES LA. 2007. Fibra de coco e resíduo de algodão para substrato de mudas de tomateiro. Horticultura Brasileira 25: 387-391.

CARRIJO OA; LIZ RS; MAKISHIMA N. 2002. Fibra da casca do coco verde como substrato agrícola. Horticultura Brasileira 20: 533-535.

DEMATTÊ MESP. 2005. Cultivo de Tillandsia kautskyi E. Pereira, bromélia brasileira em risco de extinção: comparação de substratos. Revista Brasileira de Horticultura Ornamental 11: 114-120.

JASMIM JM; TOLEDO RRV; CARNEIRO LA; MANSUR E. 2006. Fibra de coco e adubação foliar no crescimento e na nutrição de Cryptanthus sinuosus. Horticultura Brasileira 24: $309-314$

JUNQUEIRA AH; PEETZ MS. 2008. Análise conjuntural da evolução das exportações de flores e plantas ornamentais do Brasil janeiro a dezembro de 2007. Disponível em http://www.ibraflor.org. Acesso em: 20 jul. 2008.

KÖPPEN W. 1948. Climatologia; com um Estudiu de los Climas de la Tierra. México: Fondo de Cultura Económica. 478p.

MATTIUZ CFM; RODRIGUES TJD; MATTIUZ B. 2006. Aspectos fisiológicos de orquídeas cortadas. Revista Brasileira de Horticultura Ornamental 12: 21-30.

MEN S; MING X; WANG Y; LIU R; WEI C; LI Y. 2003. Genetic transformation of two species of orchid by biolistic bombardment. Plant Cell Reports 21: 592-598.

RIBEIRO JUNIOR JI. 2001. Análises estatísticas no SAEG. Viçosa: UFV. 301p.

À Fundect pela concessão de bolsa e apoio financeiro.

\section{REFERÊNCIAS}

ASSIS AM; FARIA RT; COLOMBO LA; CARVALHO JFRP. 2005. Utilização de substratos à base de coco no cultivo de Dendrobium nobile Lindl. (Orchidaceae). Acta Scientiarum Agronomy 27: 255-260.

ASSIS AM; FARIA RT; UNEMOTO LK; COLOMBO LA. 2008. Cultivo de Oncidium baueri Lindley (Orchidaceae) em substratos a base de coco. Ciência e Agrotecnologia 32: 981-985.

BANZATO DA; KRONKA SN. 1992. Experimentação agrícola. 2 ed. Jaboticabal: FUNEP. 247p.

BERNARDI AC; FARIA RT; CARVALHO JFRP; UNEMOTO LK; ASSIS AM. 2004. Desenvolvimento vegetativo de Dendrobium nobile Lindl. fertirrigadas com diferentes concentrações da solução nutritiva de Sarruge. Semina 25: 13-20.

BECHTEL H; CRIBB P; LAUNERT E. 1985. Orchideen atlas: die Kulturorchideen. Stuttgart: Ulmer, 475p.
RORIZ A (ed). 2000. 1001 Plantas e Flores. São Paulo: Europa. 258p. (CD-ROOM).

ROSA MF; SANTOS JSS; MONTENEGRO AA; ABREU FAP; ARAÚJO FBS; NORÕES ER. 2001. Caracterização do pó da casca de coco verde usado como substrato agrícola. Fortaleza: Embrapa Agroindústria Tropical. 6p. (Comunicado Técnico, 5).

ROTOR JUNIOR GB. 1952. Daylenght and temperature in relation to growth and flowering of orchids. Ithaca Cornell University Agricultural Experiment Station Bulletin 885: 3-47.

SOUZA JRP; MEHL RO; RODRIGUES JD; PEDRAS JF. 1999. Sombreamento e o desenvolvimento e produção de rabanete. Scientia Agrícola 56: 987-992.

TRIGUEIRO RM; GUERRINI IA. 2003. Uso de biossólido como substrato para produção de mudas de eucalipto. Scientia Florestalis 64: 150-162.

ZANETTI M; CAZETTA JO; JÚNIOR DM; CARVALHO SA; 2003. Uso de subprodutos de carvão vegetal na formação do portaenxerto limoeiro 'Cravo' em ambiente protegido. Revista Brasileira de Fruticultura 25: 508-512. 